\title{
Conditioned fighting and dominance in pigeons
}

FRANK N. WILLIS JR. AND AUGUSTUS R. LUMIA UNIVERSITY OF MISSOURI AT KANSAS CITY

Dominance was observed in a loft of eight racing homer pigeons, four cocks and four hens. The cock and the hen lowest in dominance as defined by frequency of displacements were conditioned to peck another pigeon in a pigeon chamber. The birds were returned to the loft and dominance was again recorded. No change in the dominance was observed as a function of the conditioning. This result is compared to previous reports of generalization of conditioned fighting.

Masure \& Allee (1934) have suggested that the dominance structure in pigeons be called peck-dominance as compared to the peck-right dominance in chickens. A distinction is necessary because in the chicken we find a dominance structure that is unidirectional and consistent, while in the pigeon we find a bi-directional dominance. In an established pigeon group any more dominant bird is sometimes displaced by less dominant birds. Dominance in a system of this kind is said to occur when a given bird elicits submissive behavior from subordinates more than $50 \%$ of the time.

Reynolds, Catania, \& Skinner (1963) found that when a pigeon was reinforced for pecking another pigeon, a complete fighting pattern typical of pigeons resulted. Although it has been said that hen pigeons never fight (Levi, 1966), Willis, Michael, \& Edwards(1966) demonstrated that a hen pigeon when conditioned to peck another bird would dominate other male and female pigeons in her home cage and in other cages. This conditioned pecking was so strong that it affected dominance over 11 months after that last training session. The observations in this study were limited to laboratory cages.

Willis (1966) found that fighting in pigeons varies as a function of the available space in a cage. It was also observed in the later study that one bird who was high in dominance in the home loft was usually clearly beaten in the fights in laboratory cages.

The question to be answered in the present study is: will birds who are low in the dominance structure in their home loft increase in dominance after they are conditioned to peck other pigeons at a high rate in a pigeon chamber similar to that described by Ferster \& Skinner (1957) except that the chamber was larger. Method

Eight sexually mature racing homer pigeons ranging in age from one to four $y$ were used as Ss. Four of the birds were cocks and four were hens. They were all housed in a common loft. Individual birds were identified with colored plastic leg bands.

The birds were housed in a loft $6 \mathrm{ft} \times 6 \mathrm{ft} \times 6 \mathrm{ft}$. Loca- tions within the loft were recorded by numbering all perches and by numbering floor locations designated by nine marked spaces of equal size. Conditioned pecking took place in a chamber 18 in. wide, 24 in. long, and 24 in. high.

The experiment was carried out in three phases. The first consisted of the observation and recording of all pecking in the home loft which resulted in one bird being displaced from a space by another. In the second phase the lowest cock and the lowest hen in the dominance structure observed in Phase 1 were maintained on $80 \%$ body weight and conditioned to peck a target bird at a high and sustained rate. The other six birds were housed individually during this time so that the observed dominance hierarchy could not shift. They were maintained on ad lib feeding. In the third phase all birds were returned to the home loft, and all displacements were again recorded. Position in the dominance structure was measured utilizing the frequency of displacement. Shoemaker (1939) suggested the term displacement to refer to any peck or advance by one bird that resulted in the retreat of another.

The birds were housed together for six months prior to the study. In Phase 1 all displacements were recorded for $2 \mathrm{~h}$ daily for a five day period. The cock and hen who were displaced most often were considered to be lowest in the hierarchy. Cock " $D$ " was chosen. The frequency with which he displaced other birds and the frequency with which they displaced him are as follows: with Cock A, 43 to 70; with Cock B, 3 to 12; and Cock C, 30 to 32 . Hen $W$ was chosen. The frequency with which she displaced other hens and the frequency with which they displaced her are as follows: with Hen X, 4 to 47; with Hen $Y, 0$ to 14 ; and with Hen $Z, 27$ to 121 . Hencock displacements were infrequent in occurrence and always resulted in cock dominance so they were not used in determining dominance.

In Phase 2, Cock D and Hen W were each placed in the conditioning chamber and were reinforced on an FR 1 schedule for pecking a red disk. After a high rate of pecking had been achieved the birds were placed on extinction in the presence of a target bird and were then shaped by successive approximation to peck the target bird. The target birds were on ad lib feeding. The schedule was gradually increased to VR 11. Conditioning was continued on the VR 11 schedule for six days. All sessions were $20 \mathrm{~min}$ in length. Total pecks per session were recorded.

In Phase 3, the two conditioned birds were placed on ad lib feeding for $24 \mathrm{~h}$, and all birds were returned 
to the home loft. Six $h$ after the birds were returned, displacements were recorded for the following three $h$. All birds were then placed on a $12 \mathrm{~h}$ food deprivation schedule in order to increase the probability of displacement (see Ritchey, 1951). The food was then returned and all displacements were again recorded for the next $7 \mathrm{~h}$.

\section{Results}

The total number of pecks per session for each of the conditioning sessions for Cock $D$ were as follows: $148,102,135,310,367,348$. The total number of pecks per session for each of the six conditioning sessions for Hen W were as follows: $92,142,362,310,351,349$. As the rates increased the conditioned birds began to fight continuously and to ignore the opening of the food chamber. It was necessary to tap on the chamber to distract them in order that the reinforcer might be delivered. It was interesting to note that Cock $D$ could not be conditioned using a hen as target bird. He would begin a courting pattern immediately and pecking could not be conditioned. After all birds were replaced in the loft with the birds on ad lib feeding, the frequency with which Cock $D$ displaced other cocks and the freuqency with which they displaced him were as follows: with Cock A, 0 to 27; with Cock B, 1 to 3; with Cock C, 0 to 14. The frequencies for Hen $W$ and her opponents were as follows: with Hen X, 3 to 18; with Hen $Y, 0$ to 6; and with Hen $Z, 1$ to 5 . Under the food deprivation condition the frequencies for Cock $D$ and his opponents were as follows: with Cock A, 2 to 47 ; with Cock B, 0 to 4 ; and with Cock $C, 4$ to 23 . It was clear that the conditioned birds were still lowest in dominance in the group; in fact, their relative position was somewhat more extreme than it was prior to the conditioning.

\section{Discussion}

Although conditioned pecking in pigeons seems to increase the bird's ability to win fights in a restricted space (Willis, Michael, \& Edwards, 1966), it does not appear to effect dominance in the home loft. A change might have been obtained if the birds from the home loft were used as target birds in the conditioning sessions, but the purpose of the present study was to examine the generalization from conditioned pecking rather than the effects on a particular opponent. Another possible source of variation is in the variety of pigeon that is conditioned. Willis, Michael, \& Edwards used a Modena hen, whereas the present study used only racing homers. It is a common observation among pigeon breeders who keep several varieties of pigeons that they differ considerably in their rates of aggression. Information about variety differences in pigeon fighting charactersitics would be valuable for the psychologist interested in fighting in birds.

References

FERSTER, C. B., \& SKINNER, B. F. Schedules of Reinforcement. New York: Appleton-Century-Crofts, 1957.

LEVI, W. Questions and answers. Amer. Pigeon J., 1966, 55, 41-42. MASURE, R. H., \& ALLEE, W. C. The social order in flocks of the common chicken and pigeon. Auk., 1934, 51, 306-327.

REYNOLDS, G. S., CATANIA, A. C., \& SKINNER, B. F. Conditioned and unconditioned aggression in pigeons. J. exp. Anal. Behav., $1963,6,73-74$.

RITCHEY, R. Dominance-subordination and territorial relationships in the common pigeon. Physiol Zool, 195 1, 24, 167-176.

SHOEMAKER, H. H. Social hierarchy in flocks of the canary. Auk., $1939,56,381-406$.

WILLIS, F. N. Fighting in pigeons as a function of available space. Psychon. Sci, 1966, 4, 315-316.

WILLIS, F. N., MICHAEL, G., \& EDWARDS, J. Persistence of condjtioned fighting in a hen pigeon. Psychon Sci, 1966, 5, 323-324. 